\title{
Impact of home exercise prescription using self- logging smartphone application on neck pain among collegiate students
}

\author{
Aakriti Dural $^{{ }^{*}}$ and Shravanthi ${ }^{1}$ \\ ${ }^{1}$ SRM College of Physiotherapy, SRM Institute of Science and Technology, Kattankulathur, \\ Kancheepuram District, Chennai 603203, India. \\ *Corresponding E-mail: aakritid191@gmail.com
}

\begin{abstract}
Non-specific neck pain is the pain in the anatomical region of the neck in which it is quite not possible to identify the exact cause. Neck pain is continuous or repeated occurring in all age groups. The aim of this study is to analyze the usage of self-logging smartphone applications as a home exercise program in a group of Collegiate students. These applications designed to train are expected to be beneficial to that particular population as long as the demonstrations are in the form of visual feedback. Based on pre-and post-type Experimental design, A total number of 40 students with neck pain were selected, according to the inclusion and exclusion criteria. Among them, Group $A$ is considered as an experimental group and Group B is considered as a control group. For the Experimental group, intervention is given for 3 weeks 4 days per week. Visual analogue scale (VAS) and Neck Pain Disability Index Questionnaire (NPDIQ) are used to assess outcome measures. Based on the measures, the study shows that the VAS and NPDIQ are statistically significant for both the experimental and control group by $p<0.005$. Therefore, it's been concluded that there is a significant improvement in both groups. But in comparison to the control group, the experimental group showed better results both statistically and clinically.
\end{abstract}

Keywords: neck pain, isometric exercises, smartphone application, home based exercises, collegiate students.

Received: 05 November, 2021

Accepted: 24 November, 2021

Published: 01 December, 2021

\section{Introduction}

Smartphone Smartphone usage has been increasing over the past few decades, this can be well described by the review done by Miakotko on the impact of smartphone usage. Where he found through the data of more than 7 Billion devices in the working population. He also found that the time associated with smartphone usage had an impact on health, social, and cultural components.

Although studies have done revealed negative impacts on human life, in one way or the other. Another part is smartphones might be used to promote health, reduce the burden they may cause on humans. For example, it is known that more than educational health-related self-logging apps 500 apps exist and have shown to have a greater impact than harming users [1]. 
Neck pain has been reported to cause symptoms leading to functional impairments and disabilities causing various functional compromises in the activities of daily living. They can range from mild to severe, chronic to acute sometimes might be life-threatening when the spinal cord is involved during accidents.

Due to the use of smartphones the neck was reported to be affected at a high rate compared to other body parts; in this context youth who are using smartphones over a long period demonstrated to have deformities such as forward head-neck posture, exaggerated upper thoracic kyphosis, and or upper crossed syndrome deformity. [2, 3] So there is no doubt that smartphones might have a great impact on the neck and associated parts such as the thorax and shoulders.

According to WHO (2018), the neck pain prevalence might exceed $40 \%$ of the World's population, the later report stated that the adult population has experienced neck pain at least one time or will experience it in their lifetime.

Mobile phones are another contributor to neck associate impairments; It also promotes communication, socialization, and economy. In some instances in business, it empowers customers to keep memories, pictures, singular information, prosperity, correspondence, and cash-related data in a single spot. It has additionally turned into a vital piece of current broadcast communications offices.

In numerous areas of the present reality, they are turning into the most reliable or only accessible phones. Cell phones and handheld gadgets, combining advanced computing capabilities, registering ability, for example, web correspondence, data recovery, online business, video, and different highlights, makes the gadget one of the necessities for the greater part of the general population in this time.

Smartphones are accepted to contribute greater risks and hazards including neck pain side effects among the clients. However, with proof of new innovation through self-logging applications, there is the possibility of switching that misconception of negative impact. Therefore, applications might be utilized to manage and treat neck pain by the self-tracking usage among users which is believed to increase the change in behavior including Home exercise programs.

Home exercise faces a lot of drawbacks including the absence of follow-up by the specialist. Patients are inclined to not pursue practices given as expected to be done effectively as trained by advisors. Smartphones are becoming reasonable and are utilized nearly by each adolescent and the use is expanding quickly in India. The cell phone is utilized for the duration of the day and is dependable with the patient. These applications intended to train and instruct are expected to be beneficial to a particular population as long as the demonstrations are in the form of visual feedback.

\section{Aim of the study}

To assess the impact of home exercise prescription using self-logging smartphone application on neck pain among collegiate students.

\section{Specific Objective}

To compare the difference between smartphone exercise prescription usage versus traditional home exercise prescription 
To assess the effects of smartphone-based exercise prescription on pain and disability among collegiate students

\section{Methodology}

Study design: Quasi Experimental

Study type: Pre and Post-test Sample method: Convenient sampling

Study duration: 4 weeks

Study setting: SRM Institute of Science and Technology

Sample size: 40 subjects ( 20 for experimental group and 20 for control comparative group)

\section{Inclusion criteria}

Students complaining of neck pain for more than 2 weeks Age 18 and above.

Owning a smartphone

\section{Exclusion criteria}

Any recent fracture in the neck region

Congenital neck deformity

Herniated disc at the cervical region cervical spondylosis and spondylolisthesis

Any specific known pathology for the pain in neck

\section{Procedure}

After the ethical clearance, subjects were selected on the basis of inclusion and exclusion criteria. The participants were explained about the smartphone application and the isometric neck exercise protocol and the consent form was obtained. MY NECK application was used in the study. It is a smartphone application which is designed in such a way that it reminds the subject as a small indicator or a big notification message that nobody can miss the exercise. All these notifications are completely customizable. This smartphone application features three proven, chiropractic neck exercise programs including video examples. It is designed to make the neck stronger, to relieve the pain and to stop the syndrome from becoming worse. The MY NECK application was installed in 20 experimental groups and the remainders were set for isometric neck exercise protocol twice per day, precisely at 6 am and at $8 \mathrm{pm}$. Patients were demonstrated clearly about the isometric neck exercises which included flexing the neck with their hand put on forehead and bend forward while pushing back, followed by extension of the neck. The subjects were asked to place their hand at the back of their head and push their head backward while pushing forward with their hands. The subjects were then instructed side bending for which they were asked to keep their head straight at chin level and put their right hand on the right side of the head. The side bending was repeated to the left side with the left hand. After side bending we instructed them rotation in which they were asked to put their left hand in the chin and turn slightly to the right. And the same was done on the left side with the left hand. All the exercise was done by holding the resistance for $10 \mathrm{sec}$ and with 3 sets.

Baseline data was collected including demography, duration of smartphone usage, pain score and disability score. 
Pain and disability was collected in the beginning of the intervention and at the end.

\section{Data Analysis}

SPSS Version 20 was used to analyze the data. The paired ' $t$ ' test and independent test was used for analysis of pretest and post-test with mean value and standard deviation value.

Table 1: Gender frequency distribution shows that $22 \%(n=10)$ were males and $75 \%(n=30)$ were females

\begin{tabular}{|l|c|c|c|c|}
\hline \multicolumn{5}{|l|}{ Demographic gender distribution } \\
\hline Variable & Frequency & Percent & Valid Percent & Cumulative Percent \\
\hline Male & 10 & 24.4 & 25 & 25 \\
\hline Female & 30 & 73.2 & 75 & 100 \\
\hline Total & 40 & 97.6 & 100 & 125 \\
\hline
\end{tabular}

Table 2: Shows that experimental group neck pain disability index scale improved from $35.9 \pm$ to $17.9 \pm 3.8$. While the visual analogue scale improved from $5.7 \pm 0.6$ to $3.9 \pm 0.7$

\begin{tabular}{|l|l|c|c|c|}
\hline \multicolumn{1}{|l|}{ Experimental group paired sample statistics } \\
\hline \multicolumn{1}{|c|}{ Outcomes } & N & Mean & SD & Std Error Mean \\
\hline EXP Neck Pain Disability Scale Pre test & 20 & 35.9 & 9.95 & 2.22651 \\
\hline EXP Neck Pain Disability Scale Post test & 20 & 17.9 & 3.86 & 0.8642 \\
\hline EXP Visual Analog Scale Pre & 20 & 5.75 & 0.68326 & 0.15278 \\
\hline EXP Visual Analog Scale & 20 & 3.99 & 0.73977 & 0.16542 \\
\hline
\end{tabular}

Within Group Comparison Experimental Group

Table 3: Shows that there was a significant improvement in both neck pain disability scale and visual analogue scale at confidence interval of $95 \%$ ( $p$ value $=0.000)$

\begin{tabular}{|c|c|c|c|c|c|}
\hline \multicolumn{2}{|c|}{ Paired t tests experimental group comparisons } & \multicolumn{2}{|c|}{ Paired Differences } & df & $\begin{array}{c}\text { Sig, } \\
\text { tailed) }\end{array}$ \\
\cline { 2 - 7 } Outcomes & Mean Diff. & SD & & & \\
\cline { 2 - 7 } & 18 & 8.63286 & 9.325 & 19 & $.000^{* * *}$ \\
\hline EXek Pain Disability Scale Pre - Post test & 1.76 & 0.59683 & 13.188 & 19 & $.000^{* * *}$ \\
\hline
\end{tabular}
$* * *$ : Significant

Control Group Descriptive Statistics.

Table 4: Shows that the control group improved from 35.4 \pm 9.2 to 9.2 on neck pain disability scale whereas the visual analogue scale improved from $5.7 \pm 0.54$ to $4.2 \pm 0.8$.

\begin{tabular}{|}
\begin{tabular}{|c|c|c|c|c|}
\hline Control group sample statistics \\
\hline Outcomes & $\mathrm{N}$ & Mean & Std. Deviation & Std. Error Mean \\
\hline Neck Pain Disability Scale Pre test & 20 & 35.4 & 9.24747 & 2.0678 \\
\hline
\end{tabular}
\end{tabular}




\begin{tabular}{|l|c|c|c|c|} 
Neck Pain Disability Scale Post test & 20 & 23.2 & 5.59699 & 1.25153 \\
\hline Visual Analog Scale Pre & 20 & 5.745 & 0.54722 & 0.12236 \\
\hline Visual Analog Scale Post & 20 & 4.295 & 0.82429 & 0.18432 \\
\hline
\end{tabular}

Controlled Group Paired t-test.

Table 5: Shows a significant improvement in both neck pain disability index scale and visual analogue scale with the mean differences of 12.2 and 1.45 respectively at confidence interval of $95 \%$ ( $p$ value $=0.00$ ).

\begin{tabular}{|l|l|l|l|l|l|}
\hline \multicolumn{1}{|c|}{ Control paired t test comparisons } & \multicolumn{2}{|c|}{ Paired Differences } & \multirow{2}{*}{$\mathrm{t}$} & df & $\begin{array}{c}\text { Sig, (2- } \\
\text { tailed) }\end{array}$ \\
\cline { 2 - 4 } & Mean Diff. & $\begin{array}{c}\text { SD } \\
\text { Deviation }\end{array}$ & & & \\
\hline Cont Neck Pain Disability Scale Pre- Post & 12.2 & 9.46795 & 5.763 & 19 & $.000^{* * *}$ \\
\hline Cont Visual Analog Scale Post- Post & 1.45 & 0.8507 & 7.623 & 19 & $.000^{* * *}$ \\
\hline
\end{tabular}

***: Significant

Independent t-test between experimental and control group

Table 6: Shows that there was a significant difference in neck pain disability index whereas visual analogue scale did not mark any significant difference

\begin{tabular}{|c|c|c|c|c|c|c|}
\hline \multicolumn{7}{|c|}{ Between groups Comparisons } \\
\hline \multicolumn{7}{|c|}{ Post-test Independent Samples Test } \\
\hline & & \multirow[b]{2}{*}{\begin{tabular}{|l} 
Mean \\
Difference
\end{tabular}} & \multirow[b]{2}{*}{\begin{tabular}{|l} 
Std. Error \\
Difference
\end{tabular}} & \multicolumn{3}{|c|}{ t-test for Equality of Means } \\
\hline & & & & $\mathrm{T}$ & $\mathrm{df}$ & $\begin{array}{l}\text { Sig. (2- } \\
\text { tailed) }\end{array}$ \\
\hline \multirow{2}{*}{\begin{tabular}{|l} 
Exp-Cont NDI \\
Scale Post test
\end{tabular}} & Equal variances assumed & -5.3 & 1.52091 & -3.485 & 38 & $.001 * * *$ \\
\hline & Equal variances not assumed & -5.3 & 1.52091 & -3.485 & 33.763 & $.001 * * *$ \\
\hline \multirow{2}{*}{\begin{tabular}{|l} 
Exp-Cont VAS \\
Post test
\end{tabular}} & Equal variances assumed & -0.305 & 0.24766 & -1.232 & 38 & $.226^{\circ 0}$ \\
\hline & Equal variances not assumed & -0.305 & 0.24766 & -1.232 & 37.564 & $.226^{\circ 0}$ \\
\hline
\end{tabular}

***: Significant, ${ }^{\circ}$ : Not significant

\section{Experimental Group Pre and Post Test.}

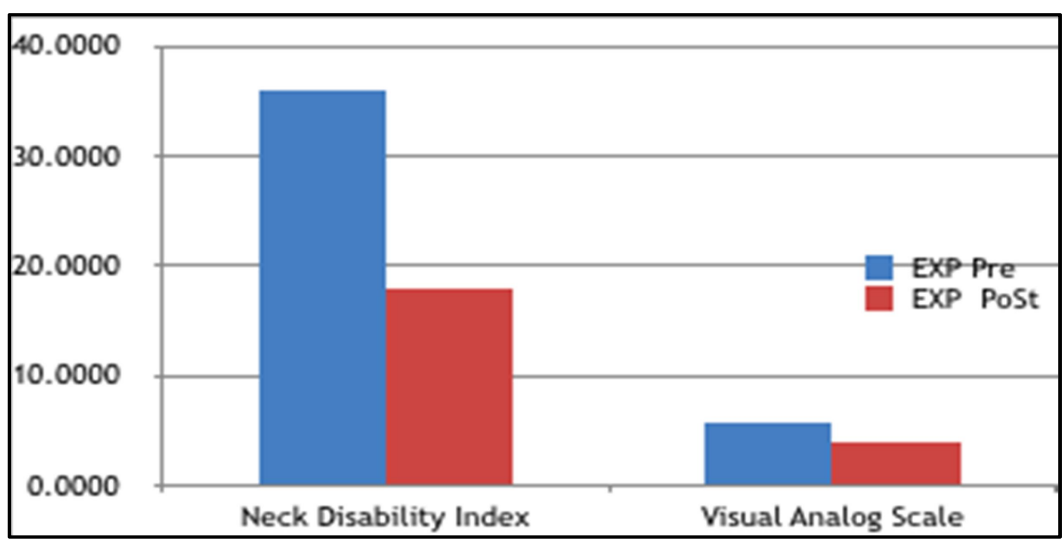




\section{Control Group Pre and Post Test}

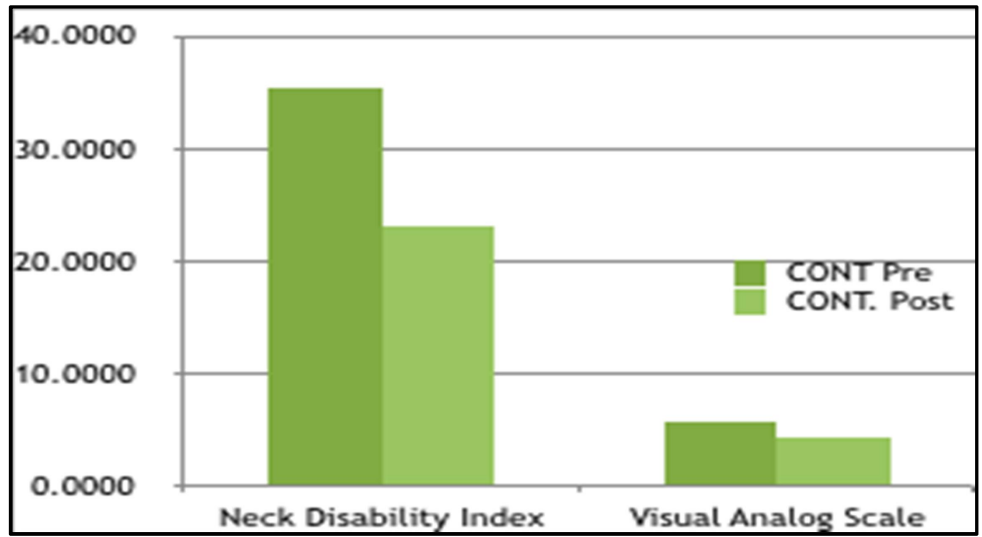

\section{Results}

According to table 1 , the gender frequency distribution $22 \%(n=10)$ were males and $75 \%(n=30)$ were females.

According to table 2, the experimental group Neck Pain Disability Index Scale improved from $35.9 \pm$ to $17.9 \pm 3.8$ while the Visual Analog Scale improved from $5.7 \pm 0.6$ to $3.9 \pm 0.7$.

According to table 3, significant improvement was found in both the Neck Pain Disability Index Scale and Visual Analog Scale at a confidence interval of $95 \%(p$-value $=0.000)$.

According to table 4, the control group improved from $35.4 \pm 9.2$ on Neck Pain Disability Index Scale whereas the Visual Analog Scale improved from $5.7 \pm 0.54$ to $4.2 \pm 0.8$.

According to table 5, there was a significant improvement in both the Neck Pain Disability Index Scale and Visual Analog Scale with a mean difference of 12.2 and 1.45 respectively at a confidence interval of $95 \%(p$ value $=0.000)$

According to table 6, there was no significant difference in Neck Pain Disability Index Scale whereas Visual Analog

The scale didn't make any significant difference.

According to Table 1 there is a decrease in the mean value of NPDIQ and VAS with a difference of $18 \%$ and $17.6 \%$ respectively which is statistically significant with a $\mathrm{p}$ value with a $\mathrm{p}$-value less than 0.05 .

According to Table 2, there is a decrease in the mean value of NPDIQ and VAS with a difference of $12.2 \%$ and $14.5 \%$ respectively which is statistically significant with a $\mathrm{p}$ value with a p-value less than 0.05 .

\section{Discussion}

The The findings from the current study revealed that the experimental group which underwent exercises with selflogging apps had superior effects significantly regarding pain reduction and disability, compared to their control group comparison the improvements were also noted but with no statistical significance.

According to Harari et al 2016, concluded that self-logging apps might be as effective in promoting health and fitness. This implies the reasons why the participants from the experimental group from the current study improved.

The current finding proposes that smartphones results outweigh the normal exercises. Verhagen et al. (2007)15 also 
reported that exercises could improve pain symptoms and disability complaints associated with the pain.

The results from this study showed a good level of significance, where the prescription using apps could replace routine home based prescription. This is due to the fact that the smartphone apps have images and videos which help the patient to follow instructions the same as the therapist wished. However, fewer studies assessed clinically the impact of using these apps in the rehabilitation journey $[2,4,5,6]$.

Few apps such as those helping people with Rheumatoid arthritis, My RA is an app, where patients report the symptoms and clinical manifestations, based on the data they provide specific exercises to manage the conditions. All these apps provided convincing data that other disorders could be targeted for home prescription purposes (Medical New Today 2018).

Although the smartphone applications such as Whatsapp, facebook and others are addictive, usage of self- logging apps could be beneficial than those later mentioned because even some apps can control and report on how daily an individual is overusing social media; with this self -logging apps can improve the general wellbeing of the population. (Lane et al. 2015).

Lifestyle changes also were reported in the literature using smartphones, although there are still a lot of challenges when it comes to validity and reliability, there is evidence that in India, such apps are producing healthy lifestyle in Youths such as weight management, daily calories intake and water drinking as reported by users. (HealthifyMe 2019).

As reported in an unpublished study by Bucyana et. al (2018), focused on smartphone usage and deep neck flexors endurance testing, the authors found that people improved their performance in strength and endurance immediately regardless of the level of smartphone addiction scores.

Siwahong et al. (2017) muscle endurance exercise had strong proof and was found for the viability of muscle reinforcing and endurance exercises in treating neck pain. Moderate proof bolstered the utilization of muscle perseverance practice in decreasing handicaps credited to neck pain.

Comparison of exercise prescription using smartphone application versus conventional physiotherapy home-based exercise prescription showed that the smartphone apps group yielded superior improvements compared to the conventional therapy group. Even though some literature comparing both therapy are less, there is a general agreement that exercise prescriptions with demonstrations through visual and auditory feedback via smartphones is much motivating and advantageous than written prescription alone. This implies that if conventional physiotherapy exercises are transformed into videos and tutorials patients would benefit a lot and this would reduce the daily exercise appointments and costs associated including tickets and medical costs.

Several Software engineers and rehabilitation workers are now partnering in designing apps to promote well-being especially in Europe and United States and through apps as the world is emerging into technology (Mafur et al. 2015, Lane et al 2015), however, this partnership is still lagging behind in developing countries.

According to the current study, the experimental group that used smartphone application exercise protocol was found to have more significance statistically and also clinically than the control group who were provided with traditional isometric neck exercise protocol.

Smartphones as of now have both negative and positive impacts on the lives of the users. On the negative side, it is commonly associated with misusing and overusing the social media over other important apps. While on the 
positive side there is now enough technology to regulate usage and manage correctly our lifestyles.

So many studies revealed that most college aged students spend more time on social media than other websites or using apps for learning purposes. This socialization issue also has led to the development of psychological disorders (Leonid Miakiotko 2017).

At last, smartphones if used wisely, there is no harm associated with the usage if the health and lifestyles apps are used.

\section{Conclusion}

Although both smartphone application exercise protocol and isometric neck exercises have been proven to be effective methods to make the neck symptoms free and to alleviate impairments associated with the syndrome from worsening. In the study when compared both smartphone self-logging application exercises showed statical significant effect.

The findings for the study should not be generalized in the general population because the participants from this study were young collegiate students with mild discomforts associated with overuse and faulty posture while using phones, all had access to the internet and smartphones and were able to use smartphones. So, the effects about this new trend in rehabilitation should be studied cautiously when it comes to its application in the clinical areas.

\section{Limitations and Recommendations}

\section{Limitations}

Among few limitations faced during the process of the current study include limited time for long term follow-up of participants. Additionally the sample size is considered to be small for studies testing impacts of interventional procedures.

The outcomes measures in this study focused on pain and disability, however the authors did not dig in-depth the factors which can contribute to symptoms such as duration of owning a smartphone, daily hours spent using smartphones, most visited applications just to list some of them.

Lastly, gender distribution was not adequate where the biggest representation was predominantly female.

\section{Recommendations}

Based on the results obtained we strongly recommend researchers who are interested in rehabilitation using technology, to continue conducting large scale studies with large numbers of populations, and with highly evidencebased medicine methods such as Randomized Controlled Trials.

To the smartphone users, the authors recommend them to use more health and self-logging apps for health purposes rather than spending more time on social media, as there are plenty of apps which help to manage various kinds of diseases including diabetes pressure wounds checks, weight loss apps, heart rate monitors, water intake and diet apps. To physiotherapists, the smartphone usage should be considered as an opportunity rather than a challenge as these apps comes to solve the issues such as forward head postures, more research collaboration between partnership with software engineers to design good apps which can be done as exercise prescription platforms with evidence-based movement. 


\section{Conclusion}

Both land therapy and pool therapy have a significant value in the TUG test wherein FES pool therapy alone has a significant value. Hence a conclusion can be drawn that when comparing the effects of pool therapy and land therapy on balance in elderly population, pool therapy is effective in improving balance among the elderly population.

\section{DECLARATIONS}

\section{Funding}

This research did not receive any specific grant from funding agencies in the public, commercial, or not-for-profit sectors.

\section{Conflicts of Interest}

The authors declared no potential conflicts of interest with respect to the research, authorship, and/or publication of this article.

\section{Acknowledgment}

I'd first like to thank my family for constant love and support through all paces of my life. Also, I would like to express my gratitude to my research guide Mr. K. Vadivelan for guiding me, having faith in me, encouraging me, and working together with immense thoughtfulness and generosity.

\section{REFERENCES}

[1] Lane et al. 2011; Marfur et al. 2015; Harari et al. 2017.

[2] De Loose V, Burnotte F, Cagnie B, Stevens V, and Van Tiggelen D: Prevalence and risk factors of neck pain in military office workers. Mil Med 2008; 173: pp. 474-479.

[3] Cagnie B, Danneels L, Van Tiggelen D, De Loose V, and Cambier D: Individual and work related risk factors for neck pain among office workers: a cross sectional study. Eur Spine J 2007; 16: pp. 679-686.

[4] Korhonen T, Ketola R, Toivonen R, Luukkonen R, Hakkanen M, and Viikari- Juntura E: Work related and individual predictors for incident neck pain among office employees working with video display units. Occup Environ Med 2003; 60: pp.

[5] 5. Wahlström J, Hagberg M, Toomingas A, and Wigaeus Tornqvist E: Perceived muscular tension, job strain, physical exposure, and associations with neck pain among VDU users; a prospective cohort study. Occup Environ Med 2004; 61: pp.

[6] Hush JM, Michaleff Z, Maher CG, and Refshauge K: Individual, physical and psychological risk factors for neck pain in Australian office workers: a 1-year longitudinal study. Eur Spine J 2009; 18: pp. 1532- 1540.

[7] Ariens GA, Bongers PM, Hoogendoorn WE, van der Wal G, and van Mechelen W: High physical and psychosocial load at work and sickness absence due to neck pain. Scand J Work Environ Health 2002; 28: pp. 222-231.

[8] Cote P, van der Velde G, Cassidy JD, Carroll LJ, Hogg-Jonhson S, Holm LW, et al: The burden and determinants of neck pain in workers; results of the bone and joint decade 2000-2010 task force on ne ck pain and its associated disorders. J Manipulative Physiol Ther 2009; 32: pp. S70-86.

[9] Borghouts JA, Koes BW, Vondeling H, and Bouter LM: Cost-of-illness of neck pain in the Netherlands in 1996. Pain 1999; 80: pp. 629-636

[10] Green BN: A literature review of neck pain associated with computer use: public health implications. J Can Chiropr Assoc 2008; 52: pp. 161-167

[11] Borghouts JA, Koes BW, and Bouter LM: The clinical course and prognostic factors of non-specific neck pain: a 
systematic review. Pain 1998; 77: pp. 1-13

[12] Kietrys DM, Galper JS, and Verno V: Effects of at-work exercises on computer operators. Work 2007; 28: pp. 67-75

[13] Blangsted AK, Sogaard K, Hansen EA, Hannerz H, and Sjogaard G: One-year randomized controlled trial with different physical-activity programs to reduce musculoskeletal symptoms in the neck and shoulders among office workers. Scand J Work Environ Health 2008; 34: pp. 55-65

[14] Linton SJ, and van Tulder MW: Preventive interventions for back and neck pain problems: what is the evidence? Spine 2001; 26: pp. 778-787

[15] Verhagen AP, Karels C, Bierma-Zeinstra SM, Feleus A, Dahaghin S, Burdorf A, et al: Exercise proves effective in a systematic review of work-related complaints of the arm, neck, or shoulder. J Clin Epidemiol 2007; 60: pp. 110-117

[16] Sarig-Bahat H: Evidence for exercise therapy in mechanical neck disorders. Man Ther 2003; 8: pp. 10-20

[17] Waersted M, Hanvold TN, and Veiersted KB: Computer work and musculoskeletal disorders of the neck and upper extremity: a systematic review. BMC Musculoskelet Disord 2010; 11: pp. 79

[18] Van Poppel MN, Hooftman WE, and Koes BW: An update of a systematic review of controlled clinical trials on the primary prevention of back pain at the workplace. Occup Med (Lond) 2004; 54: pp. 345-352

[19] Maher CG, Sherrington C, Herbert RD, Moseley AM, and Elkins M: Reliability of the PEDro scale for rating quality of randomized controlled trials. Phys Ther 2003; 83: pp. 713-721.

[20] Machado LA, de Souza MS, Ferreira PH, and Ferreira ML: The McKenzie method for low back pain: a systematic review of the literature with a meta-analysis approach. Spine (Phila Pa 1976) 2006; 31: pp. E254- E262

[21] Van der Beek AJ, and Frings-Dresen MH: Assessment of mechanical exposure in ergonomic epidemiology. Occup Environ Med 1998; 55: pp. 291-299

[22] Wahlström J: Ergonomics, musculoskeletal disorders and computer work. Occup Med (Lond) 2005; 55: pp. 168-176

[23] Van Tulder M, Furlan A, Bombardier C, and Bouter L: Updated method guidelines for systematic reviews in the Cochrane collaboration back review group. Spine (Phila Pa 1976) 2003; 28: pp. 1290-1299

[24] Liddle SD, Baxter GD, and Gracey JH: Exercise and chronic low back pain: what works? Pain 2004; 107: pp. 176190

[25] Hamberg-van Reenen HH, Visser B, van der Beek AJ, Blatter BM, van Dieen JH, and van Mechelen W: The effect of a resistance-training program on muscle strength, physical workload, muscle fatigue and musculoskeletal discomfort: an experiment. Appl Ergon 2009; 40: pp. 396-403

[26] Sjogren T, Nissinen KJ, Jarvenpaa SK, Ojanen MT, Vanharanta H, and Malkia EA: Effects of a workplace physical exercise intervention on the intensity of headache and neck and shoulder symptoms and upper extremity muscular strength of office workers: a cluster randomized controlled cross-over trial. Pain 2005; 116: pp. 119-128

[27] Gross AR, Kaplan F, Huang S, Khan M, Santaguida Abdel-Wahab M, Rosenblatt E, Holmberg O, Meghzifene A, AbrahamJ, Nelon L, et al. Taussig Cancer Institute 2011 Publications. studies. 2011;11(2):161-3

[28] 2010 Task Force on Neck Pain and Its Associated Disorders: executive summary. Spine 2008, 33: S5-S

[29] Hurwitz EL, Carragee EJ, van der Velde G, Carroll LJ, Nordin M, Guzman J et al.: Treatment of neck pain: noninvasive interventions: results of the Bone and Joint Decade 2000-2010 Task Force on Neck Pain and Its Associated Disorders. J Manipulative Physiol Ther 2009, 32: S141-S175

[30] Eur Spine J. 2006 Jun; 15(6): 834-848. Published online 2005 Jul 6. doi: [10.1007/ s00586-004-0864-4]

[31] Uthaikhup S, Prasert R, Paungmali A, Boontha K. Altered pain sensitivity in elderly women with chronic neck pain. PloS one. 2015;10(6):e0128946 